\title{
Are virtual reference services color blind?
}

\author{
Pnina Shachaf and Sarah Horowitz
}

School of Library and Information Science, Indiana University, 1320 East 10th Street, LI005A, Bloomington, IN 47405-3907, USA. shachaf@indiana.edu

\begin{abstract}
This study reports an experiment that examines whether librarians provide equitable virtual reference services to diverse user groups. The relative absence of social cues in the virtual environment may mean greater equality of services though at the same time greater inequalities may arise as librarians can become less self-aware online. Findings indicate that the quality of service librarians provide to African Americans and Arabs is lower than the quality of service they provide to Caucasian, Hispanic, Asian, and Jewish students. This study adds to the knowledge of subjective bias in the virtual environment by specifying those that are discriminated against online, identifying the kinds of discriminatory actions of virtual reference librarians, and identifying the type of queries that more frequently result in unbiased service.
\end{abstract}

\section{Introduction}

Virtual reference, which allows users to connect easily with librarians online, is becoming highly popular. Librarians answer thousands of questions every day over the Internet (Coffman \& Arret, 2004). Although the service is maturing much more research is still needed. In particular, there is a need to gain a better understanding of the role of virtual reference in providing services to diverse and cross-cultural user groups (Shachaf, Hara, Meho, Kwon, Li, Sakai, \& Lankes, 2005). This research gap is now becoming more important with the increased numbers of diverse and non-traditional students attending colleges and universities.

Today more than ever minorities and international students attend higher education institutions in North America (Curry \& Copeman, 2005, Whitmire, 1999 and Whitmire, 2003). These diverse user groups are making growing use of library and reference services (Curry \& Copeman, 2005, Liu \& Redfern, 1997, Whitmire, 1999, Whitmire, 2003 and Zoe \& DiMartino, 2000). They use the academic library heavily (African American students use the library more than White students) and request more assistance in searching databases (non-native English speakers compared with native English speakers) (Whitmire, 1999, Whitmire, 2003 and Zoe \& DiMartino, 2000). They may also heavily use virtual reference services.

The provision of online reference services, specifically via e-mail, enables users who were uncomfortable approaching a librarian in person to submit anonymous questions to a virtual reference service (Coffman, 2003). Likewise, certain user groups do not come to the library due to physical disabilities, scheduling constraints, or geographical distance. 
These users too might find virtual reference to be more accessible for their needs, as it provides services to users any time, any place. Users can send reference queries via email whenever they have questions (Bushallow-Wilbur et al., 1996 and Stacy-Bates, 2003).

However, providing reference services to diverse user groups is a challenging task that involves overcoming many barriers (Curry \& Copeman, 2005). The American Library Association's (1995) code of ethics guides reference librarians to provide unbiased responses to all requests and users. Additionally, Section 201(a) of the Civil Rights Act of 1964 (42 USC § 2000a(a) (1964)) specifies that "all persons shall be entitled to the full and equal enjoyment of the goods, services, facilities, privileges, advantages, and accommodations of any place of public accommodation, as defined in this section, without discrimination or segregation on the ground of race, color, religion, or national origin." Yet it is possible that reference librarians in academic libraries provide biased reference service. Providing services to diverse user groups over the Internet (virtual reference) may increase or decrease such bias.

It is possible that reference services will be more equal when provided online because during the reference interview (via e-mail) blatant differences do not interfere. Also, email mediates intercultural communication and reduces miscommunication (Shachaf, 2005). When communication is mediated by computers, social presence is reduced (Sproull \& Keisler, 1986). Interactions are more impersonal and task oriented because of the lack of social cues, lack of context, and lack of non-verbal behavior. The decrease in social cues can have a democratizing effect on communication resulting, for example, in status equalization. The relative absence of social cues may mean greater equality of services in the virtual environment. Due to the lack of social cues in e-mail-mediated communication, virtual reference can facilitate the provision of unbiased service to diverse user groups.

E-mail bears many challenges for librarians in the provision of reference services, however. Primarily due to the lack of non-verbal cues during the reference interview, misunderstanding can occur (Abels, 1996). Furthermore, discrimination is more likely to be expressed overtly due to the anonymous, spontaneous, impersonal, and uninhibited nature of computer-mediated communication (Glaser \& Kahn, 2005); librarians can express themselves in less self-conscious and socially desirable ways. Although librarians will not be likely to deny some resources or services on the basis of group membership, they may find an excuse to behave discriminatorily at the moment. In computer networks, for example, higher levels of hostile, uninhibited, and flaming behavior have been observed (Douglas \& McGarty, 2001). Douglas and McGarty (2001) claimed that it is likely that in the virtual environment subjective bias will be similar to the pre-civil rights era and that greater inequality will arise. This discrimination can be seen as similar to that found in studies from the pre-civil rights act era that found formal written requests for service to be rejected more than in person requests by minorities (Glaser \& Kahn, 2005). In providing virtual reference services, librarians can become less self-aware and less likely to monitor their behavior and therefore more likely to react on impulses that would normally be inhibited. Thus, it is also possible that greater inequalities will arise. While it 
is possible that inequality in reference services will increase in the virtual environment due to the deregulating effect it has, it is likewise possible that librarians may be able to provide unbiased service online. This study addresses the lacuna in studies that examine discrimination online (Glaser \& Kahn, 2005). The study aims to add to the knowledge of subjective bias in the virtual environment. Specifically, it addresses the need for more studies that examine service discrimination by librarians and aims to identify the kinds of discriminatory actions of virtual reference librarians. This study focuses on the following research question: Are virtual reference services color and gender blind and are they providing unbiased services to diverse user groups? More specifically, this study clarifies who is more likely to be discriminated against online by virtual reference librarians.

\section{Procedures}

An experiment using scenarios of information needs was conducted. The experimental feature of the study is that the requests have six versions that differed only in the implicit ethnicity of the user involved in the six incidents. Each version of the request represented one ethnic group: African American, Hispanic, Asian, or Caucasian; or one religious identification: Christian (Caucasian), Muslim, or Jewish. The targeted reference service received a version of the same type of request but with a different user name (indicating a different ethnic group or religious affiliation). In this way, it was possible to determine whether librarians provide equivalent service to different groups when salience of diversity (e.g., ethnic group) is not an obvious factor and when all other factors are constant.

This method is in particular relevant when attitude and behavior variability are measured on sensitive variables, such as diversity. If people avoid blatant discrimination to avoid social ramifications they might monitor their discriminatory behavior closely if they believe the study is related to race (Bushman \& Bonacci, 2004).

There are many ways that have been applied to evaluate reference services; these have focused on the types of questions asked at the desk, the accuracy of the information provided by the reference librarian in her reply, user satisfaction with the reference service, librarian's behavior, and library collections (Gross \& Saxton, 2002). Some researchers applied the same methods to evaluate virtual reference services while others advised the development and use of new ways to evaluate virtual reference services (Hernon \& Calvert, 2005, McClure et al., 2002 and White, 2001). At the same time, the need to conduct more evaluative studies of virtual reference service has likewise been emphasized (White, 2001).

Unobtrusive methods for traditional reference services evaluation were used for decades.

One of the most well known unobtrusive studies was conducted about two decades ago and generated many replications which consistently found that librarians' responses are accurate only 55\% of time (Hernon \& McClure, 1986). Whitlatch, 1989 and Whitlatch, 2001 emphasized that this method can be used effectively to evaluate virtual reference as well. 
This study applied an unobtrusive method, where responses to queries are assessed without the reference service providers knowing that they are being studied. Several studies report findings from unobtrusive studies that assess the quality of virtual reference services (Carter \& Janes, 2003, Kaske \& Arnold, 2002 and Stacy-Bates, 2003). The assumption is that, if an obtrusive approach were employed, librarians would more likely try to act in a fair and impartial way because the potential for discrimination and inequitable service would be obvious.

\section{Data collection}

During summer 2005, all Association of Research Libraries (ARL) member libraries were invited by an e-mail sent to the head of the reference department to participate in the study. Two batches of requests were sent and 23 libraries agreed to take part in this study - for a participation percentage of $19 \%$. These and other libraries raised a concern that their services to unaffiliated users (users who are not affiliated with the institution) are limited. "Accepting questions from non affiliates of the library has both pros, such as good public image, and cons, such as diverting reference service providers' time from serving affiliates" (Stacy-Bates, 2003, pp. 60-61). Another frequent concern that librarians have raised when asked to participate was that they cannot decide to participate due to the fact that they provide virtual reference as part of a collaborative effort. Despite the fact that the recruitment letter and the informed consent form specified that the libraries which agreed to participate would receive e-mail queries, many libraries interpreted virtual reference service as primarily chat or real time service, and not e-mail or Web form. However, White (2001) defines virtual reference service as "an information access service in which people ask questions via electronic means (such as e-mail and Web forms). In turn knowledgeable individuals answer the questions, and responses are transmitted via electronic means" (p. 211). Following Stacy-Bates' (2003) definition, virtual reference service in this study refers to e-mail: either a mail-to link or a Web form that users can fill out to ask reference questions.

In the fall of 2005, e-mail reference requests were sent to the 23 libraries; each library received one request per week during six consecutive weeks. Each library received five different types of requests using six different names and six different e-mail accounts. Every week, 23 messages were sent from one e-mail account (one user), one per library, five from each type of question. The chronological order of the users' messages that was used was defined by alphabetic order of user's last name. Using this order, it was possible to overcome the chance that current events might confound our results. For example, just before the first 23 messages were about to be sent, during the second week of September 2005, racial and class issues were discussed in the media following Hurricane Katrina's devastation of New Orleans. During the same week, Israel withdrew from Gaza. These two events could potentially influence the results of the study. Any informed decision about the order of the users could potentially threaten the reliability of the results. For that reason, a randomly arranged order (alphabetical order of user's last name) was used for data collection. 
The names that were used in this study were selected from lists of names (or baby names) that are available online. The names that represent ethnic groups are Latoya Johnson for African-American, Rosa Manuz for Hispanic, Chang Su for Asian (Chinese), and Mary Anderson for Caucasian. Representing religious group affiliation, the names that were used are Mary Anderson for Christian, Ahmed Ibrahim for Muslim, and Moshe Cohen for Jewish. A total of six names were included; four of them are female names and two are male names.

Five reference queries were used in this study; three of them followed Stacy-Bates' (2003, p. 61) examples, which according to her study are expected to be answered by more than $90 \%$ of the libraries. Following these findings, it was expected that most of the participant ARL libraries will respond to unaffiliated users on these three queries. However, it was also expected that academic libraries will not be inclined to answer queries $4-5$ when made by unaffiliated users. When the virtual reference service policies of the participant libraries were examined, it was found that most of them limit their virtual reference services to unaffiliated users. These policies specify that the library will answer unaffiliated users' requests only when they submit questions that are specific to the library or university. Assuming that reference librarians are aware of the policies for unaffiliated users, it was expected that they will not provide support to unaffiliated users with their topical requests. Finally, it was assumed that reference librarians will comply with intellectual property and copyrights laws and will follow the terms of use of electronic journals and databases. Therefore, it was expected that the fifth request will be rejected by the participant libraries. These are the queries that were sent:

1. Dissertation query (Stacy-Bates, 2003): Can you tell me the title of [name]'s dissertation? [She/He] finished [his/her] degree at [institution name] in [year]. Do you have it in your library? How can I obtain a copy of this dissertation?

2. Sports team query (Stacy-Bates, 2003): How did [sports team name] become the name for [institution name]'s sports teams? Can you refer me to a book or article that discusses it?

3. Population query (Stacy-Bates, 2003): Could you tell me the population of [institution's city name] in 1963 and 1993?

4. Subject query: Could you help me find information about [special collection topic]? Can you send me copies of articles on this topic?

5. Article query: Can you send me by e-mail a copy of the article "Free Indirect Discourse and Narrative Authority in Emma" by D.P. Gunn?

Before the questions were sent, information about each institution was collected into a file. This information was later used when preparing the specific questions about information unique to the institution. Each institution file included (1) details of a dissertation that was awarded by the institution in 1964 (or the earliest date thereafter) which was identified using Dissertation Abstracts, (2) sports team's name as identified 
from a search on the parent institution Web site, (3) topics of special collections for the subject query, and (4) policies about service restrictions for unaffiliated users and response time. In addition, a full-text article that was available via EBSCO Academic Search Premier was selected for the fifth question. It was assumed that any of the ARL libraries will have access to the full-text of this article, but that due to licensing restriction librarians will be less likely to send the full text of the article.

A total of 138 queries were sent during September and October 2005. The counterbalanced method was used to avoid variables confounding. The technique in counterbalancing is to make sure that each user name appears in each position an equal number of times. Each user sent the same number of messages, each library received only one request from each user, and each library received a specific type of request only once. Each week, a different question was received at the reference service of an institution from a different user. ${ }^{1}$

Each of the repeated requests, which were sent during the sixth week, was different from the first request an institution received during the first week of data collection. These requests had a different article title, dissertation title, and years but followed exactly the same text.

Because it was clear that if the requests were to be sent to the library on the same day of the week and at the same hour of the day librarians would be suspicious about this pattern of requests coming in from unaffiliated users, the requests were sent during different days and hours. As a result, some of the messages were sent during the weekend. This created some difficulties in the interpretation of the findings later, such as interpreting the results for response time.

\section{Data analysis}

All 138 queries were uploaded into Nvivo2.0. Nvivo is a QSR software that supports qualitative analysis. Using Nvivo facilitates content analysis and the search for frequencies and co-occurrences of codes and attributes. Because the transactions' content categories had to be correlated with the attributes of each transaction, such as user name, response time, length of reply, and type of question, to name a few, the use of Nvivo was instrumental. Further, Nvivo matrix capabilities facilitate the identification of patterns among categories and also between categories and attributes.

Each transaction was classified according to 12 attributes (each with multiple values) and 59 categories, initially. Content categories were developed from the data and were also based on the International Federation of Library Associations (IFLA) digital reference guidelines (International Federation of Library Associations, 2005), the Reference and User Services Association (RUSA) guidelines for implementing and maintaining virtual reference services (Reference and User Services Association, 2004b), and on the RUSA guidelines for behavioral performance of reference and information service providers (Reference and User Services Association, 2004a). After all the transactions were coded by one coder, $10 \%$ of the data was coded by a second coder to evaluate the level of inter- 
coder reliability. The coding was followed by a discussion among the coders that clarified codes and modified the coding scheme. The final coding scheme was decreased to 23 categories (Table 1). Three iterations of coding by the two coders were required until an acceptable level of agreement between the two coders was reached (above 90\%). A different set of transactions $(10 \%$ of the data) was coded per iteration. The final result of the inter-coder reliability was $92 \%$ (number of agreements divided by the sum of number of agreements and disagreement).

\section{Table 1. Coding scheme}

\begin{tabular}{|l|l|}
\hline Code & Description \\
\hline First name & Librarian addressed the user by first name (e.g. Mary, Moshe) \\
\hline Full name & $\begin{array}{l}\text { Librarian addressed the user by full name (e.g., Mary Anderson, Moshe } \\
\text { Cohen) }\end{array}$ \\
\hline With honorific & The user's name appeared with honorific (Ms. Mrs.) \\
\hline Greetings & Librarians address the user with greetings (Hello, Hi, Greetings) \\
\hline $\begin{array}{l}\text { Reiteration of request } \\
\text { included in reply }\end{array}$ & Librarian reiterated user request in reply \\
\hline $\begin{array}{l}\text { Automatic reiteration of } \\
\text { request include in reply }\end{array}$ & Automatic inclusion of user's request in librarian's reply \\
\hline Article sent & Librarian sent the full text of the requested article to the user \\
\hline List of sources suggested & Librarian suggested a list of sources on the topic of interest \\
\hline Population question answered & Librarian provided population numbers for both years \\
\hline $\begin{array}{l}\text { Full dissertation citation } \\
\text { provided }\end{array}$ & Librarian provided the full citation of the dissertation \\
\hline Mascot explained & Librarian explained the source of the Mascot name \\
\hline Instructions provided & $\begin{array}{l}\text { Librarian provided instructions on how to use a resource (ILL, local } \\
\text { library, database) }\end{array}$ \\
\hline Referral was made & Librarian referred the user (Local library, librarian, ILL) \\
\hline Policies explained & $\begin{array}{l}\text { Librarian explained policies (ILL, opening hours, unaffiliated users, type } \\
\text { of questions answered, copy and download) }\end{array}$ \\
\hline Search strategy explained & Librarian explained search strategy used to find answer \\
\hline $\begin{array}{l}\text { Evaluative remarks were } \\
\text { given }\end{array}$ & Librarian made evaluative remarks on answer \\
\hline Follow-up & $\begin{array}{l}\text { Librarian made follow-up remarks (e.g., please let me know if this } \\
\text { answers your question) }\end{array}$ \\
\hline Name of librarian & Librarian signed his/her name \\
\hline Department & Librarian signed his/her departmental affiliation \\
\hline Contact info & Librarian provided contact information \\
\hline $\begin{array}{l}\text { Concluding remarks were } \\
\text { made }\end{array}$ & Librarian made concluding remarks (e.g., I hope this is helpful) \\
\hline Thank you & Librarian wrote thank you to user at beginning or end of reply \\
\hline Apologies & Librarian apologized \\
\hline
\end{tabular}

Limitations of this study are due mainly to the small sample size, which could not support cross tabulation among user groups on most content categories. Future studies should increase the number of institutions and involve more transactions to determine the statistical significance of the findings. 


\section{Results}

The content analysis of the 138 e-mail transactions revealed differences in the quality of service that virtual reference librarians provide to various users groups. This is the case when African American and Arab users are compared with Whites, both Christian and Jewish users. Table 2 summarizes the frequencies of codes for each user group. Each of the ethnic or religious groups is represented by a name; in this section a shorter version of the names will be used; each user group will be indicated by first name of the user (for example, Mary instead of Mary Anderson and Moshe instead of Moshe Cohen).

\section{Table 2. Code frequencies per user group}

\begin{tabular}{|l|l|l|l|l|l|l|}
\hline Code & Mary & Moshe & Latoya & Ahmed & Rosa & Chang \\
\hline First name & 7 & 8 & 9 & 5 & 9 & 5 \\
\hline Full name & 3 & 2 & 2 & 4 & 2 & 6 \\
\hline With honorific & 5 & 2 & 2 & 0 & 1 & 0 \\
\hline Greetings & 13 & 15 & 14 & 13 & 16 & 15 \\
\hline Reiteration of request included in reply & 2 & 1 & 2 & 1 & 1 & 0 \\
\hline Automatic reiteration of request include in reply & 18 & 19 & 22 & 19 & 22 & 20 \\
\hline Article sent & 0 & 1 & 1 & 2 & 0 & 1 \\
\hline List of sources suggested & 1 & 0 & 0 & 0 & 0 & 0 \\
\hline Population question answered & 4 & 2 & 1 & 3 & 3 & 3 \\
\hline Full dissertation citation provided & 4 & 3 & 2 & 2 & 2 & 1 \\
\hline Mascot explained & 1 & 2 & 1 & 0 & 5 & 1 \\
\hline Instruction provided & 4 & 3 & 1 & 3 & 1 & 1 \\
\hline Referral was made & 10 & 10 & 17 & 10 & 13 & 14 \\
\hline Policies explained & 11 & 7 & 6 & 8 & 6 & 4 \\
\hline Search strategy explained & 1 & 2 & 2 & 3 & 2 & 2 \\
\hline Evaluative remarks were given & 0 & 0 & 1 & 2 & 0 & 0 \\
\hline Follow-up & 4 & 8 & 4 & 4 & 5 & 2 \\
\hline Name of librarian & 14 & 13 & 12 & 13 & 16 & 14 \\
\hline Department & 10 & 9 & 6 & 7 & 10 & 11 \\
\hline Contact info & 5 & 3 & 4 & 5 & 8 & 5 \\
\hline Concluding remarks were made & 6 & 11 & 8 & 6 & 6 & 3 \\
\hline Thank you & 8 & 6 & 5 & 4 & 7 & 7 \\
\hline Apologies & 0 & 1 & 3 & 2 & 1 & 2 \\
\hline
\end{tabular}

Fig. 1 illustrates the difference in the average amount of time it took a librarian to respond to users' requests for each user name. It is very clear that Moshe is getting the quickest reply and the best level of service. It is also obvious that Ahmed is getting the worst level of service as it takes the librarian on average much longer to reply to his requests. At this point, it should be clarified that Latoya and Mary can only be compared to one another and not to the other users since these requests were sent during the weekend. Yet it is clear that Mary's response time is shorter when compared with Latoya's. 


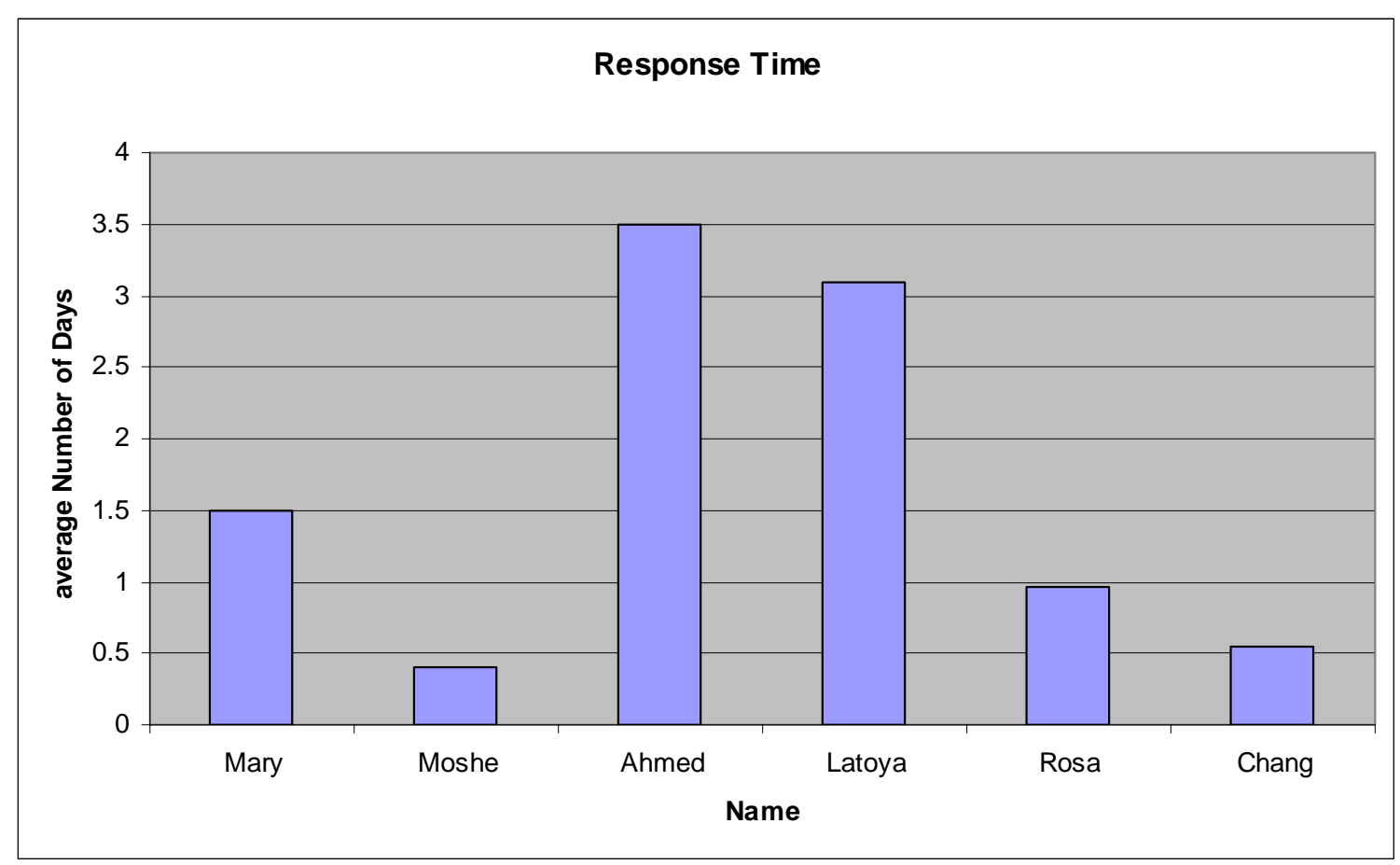

Fig. 1. Response time (average number of days).

Another way to look at these results is by examining the number of days it takes for each of the users to get a reply. Fig. 2 describes the number of days it took the librarians to respond to the user's requests. Again, while Mary and Moshe receive most of the replies within the same day or during the following day, some of the replies to Latoya and Ahmed are sent weeks after they were submitted (some of the messages that Ahmed received arrived on the 31st day after sending the requests, and Latoya received some of the replies on the 18th and 21 st days after the requests were sent).

Fig. 3 illustrates the differences among user groups in the length of replies the user received from the librarian. The number of words in the reply is an indication of the reply length; for each user the average length of reply was calculated. Again, Moshe and Mary are getting longer messages than the other user groups and a different level of service is clearly exhibited. 


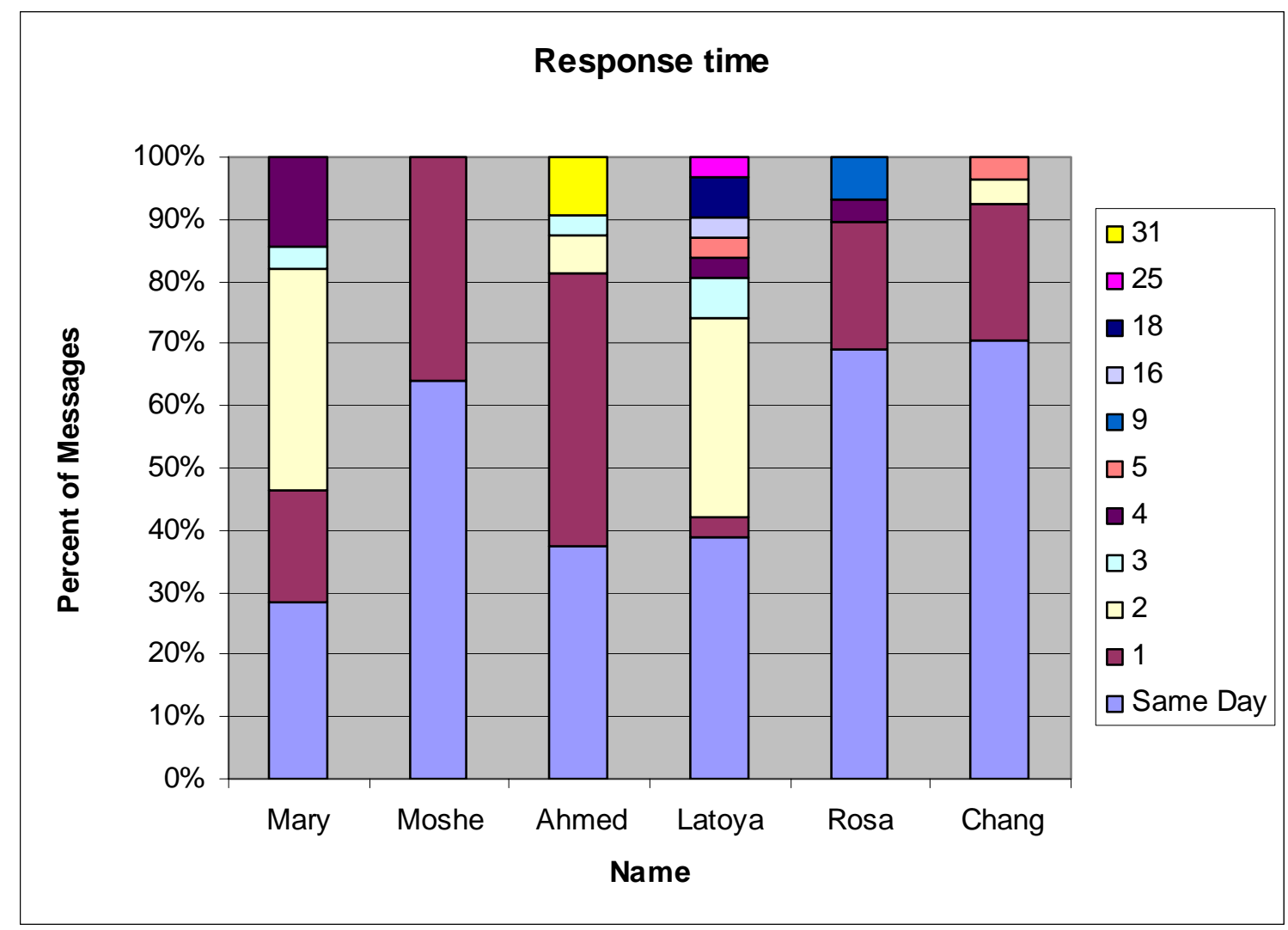

Fig. 2. Response time (number of days it took the librarian to reply).

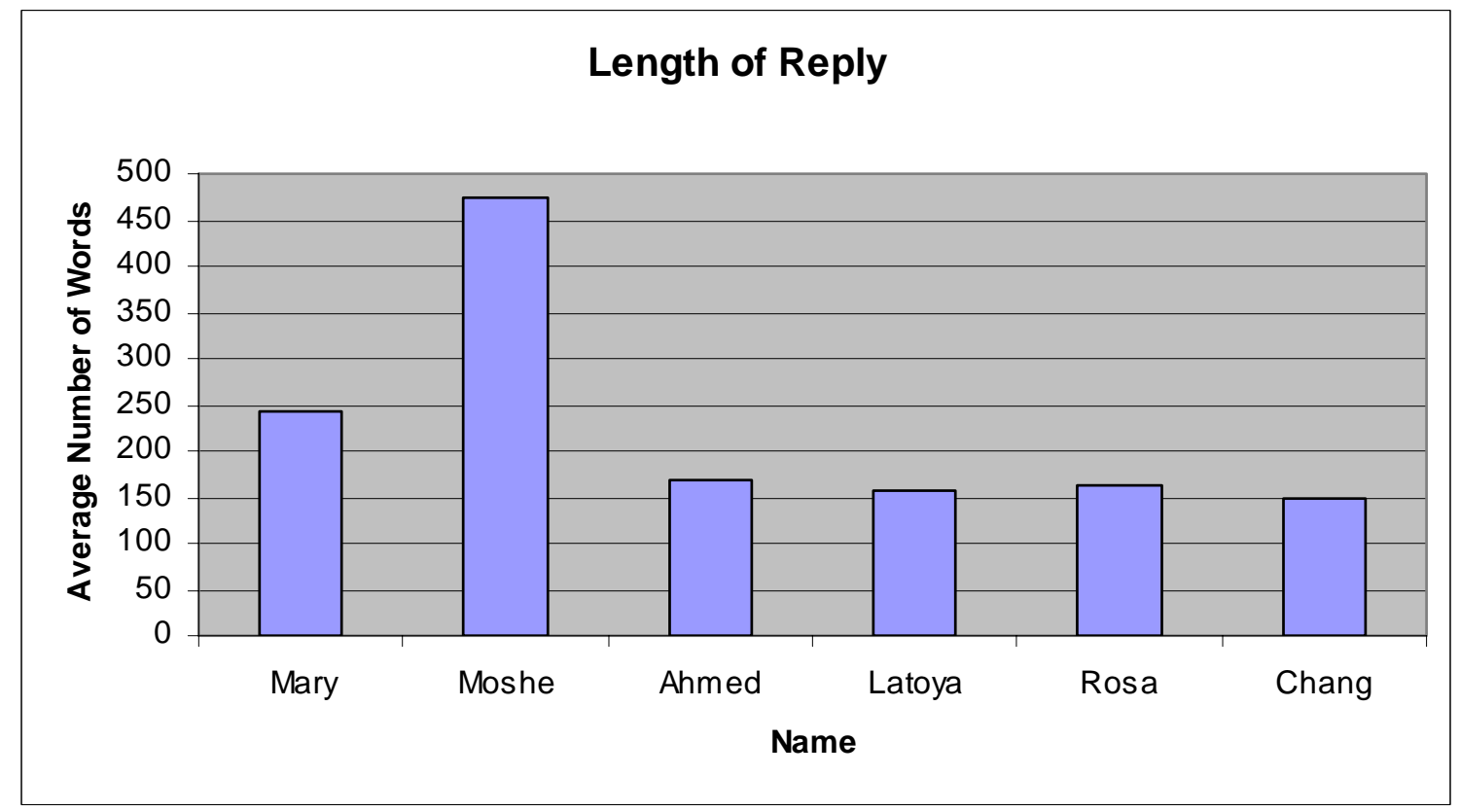

Fig. 3. Length of reply. 
Fig. 4 illustrates the level of service each user group received in terms of the ratio of the number of messages that answered the request to the number of messages the librarian sent the user. In this figure, the lower the difference between the number of answers and the number of messages the higher the level of service the user received. In other words, if the user receives one response that answers the question, she will be satisfied. On the other hand, when a user receives many messages but still does not receive a reply to the request, she will not be satisfied with the service. When comparing users, it is evident that Mary and Moshe receive the highest level of service in this category while the level of service for Ahmed and Latoya is the lowest. Ahmed and Latoya received many messages but fewer answers, compared with Moshe and Mary, who received proportionally many more answers out of the messages they received.

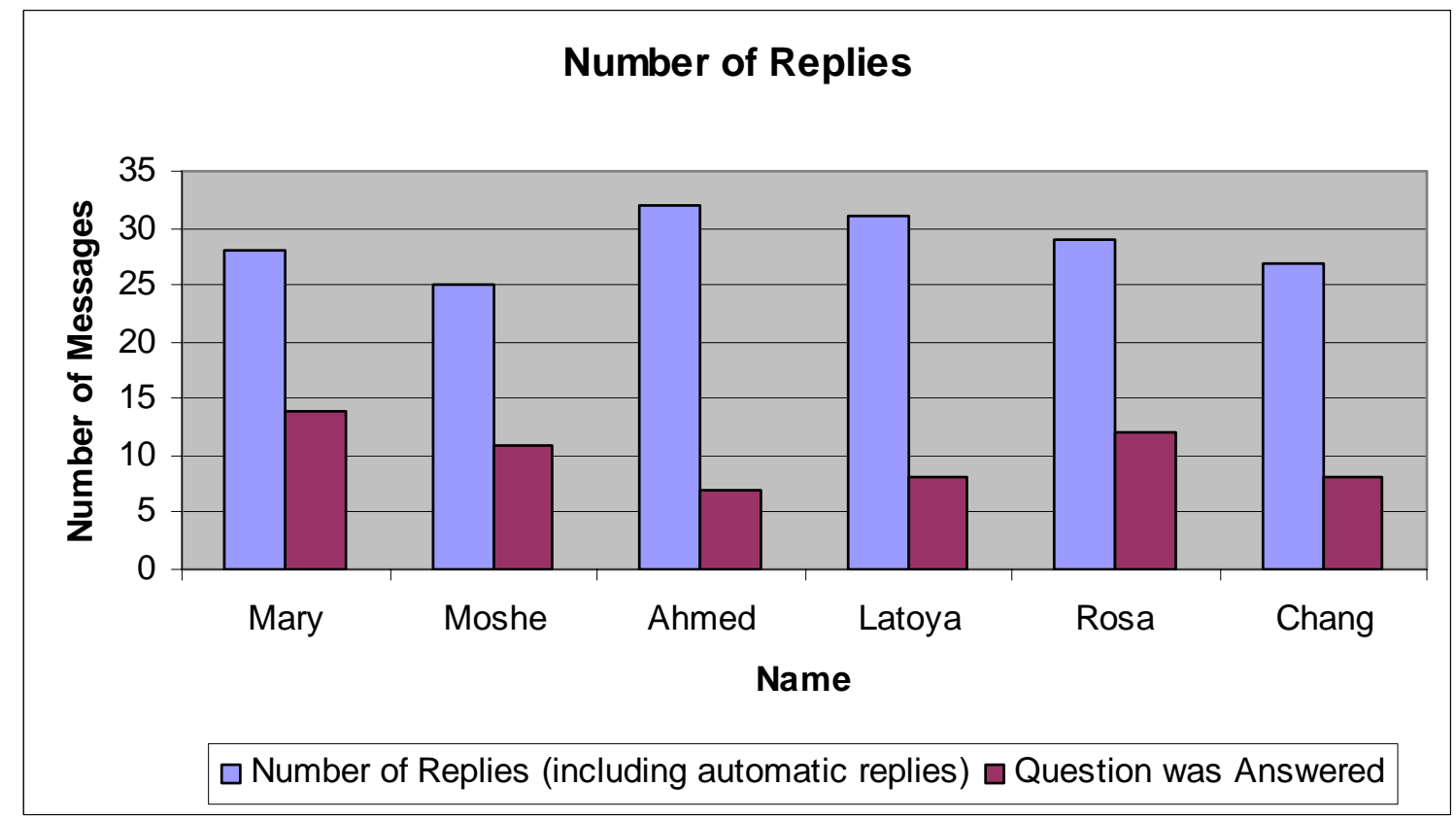

Fig. 4. Number of messages received.

As Fig. 5 illustrates, overall Mary, Moshe, and Rosa receive more answers to their requests, while Ahmed, Latoya, and Chang do not. This trend is even more clearly represented in Fig. 6, where it can be seen that on almost any type of question Mary gets more answers than do Ahmed and Latoya. Overall, most of the time the librarians did not provide the answers to questions that they were not expected to answer according to their institutional policies and licensing agreements (e.g., full-text article or topical question). This is described in Fig. 7, which shows many more responses to the first three types of questions (dissertation, mascot, and population) than to the last two types of questions (full-text article and topical). 


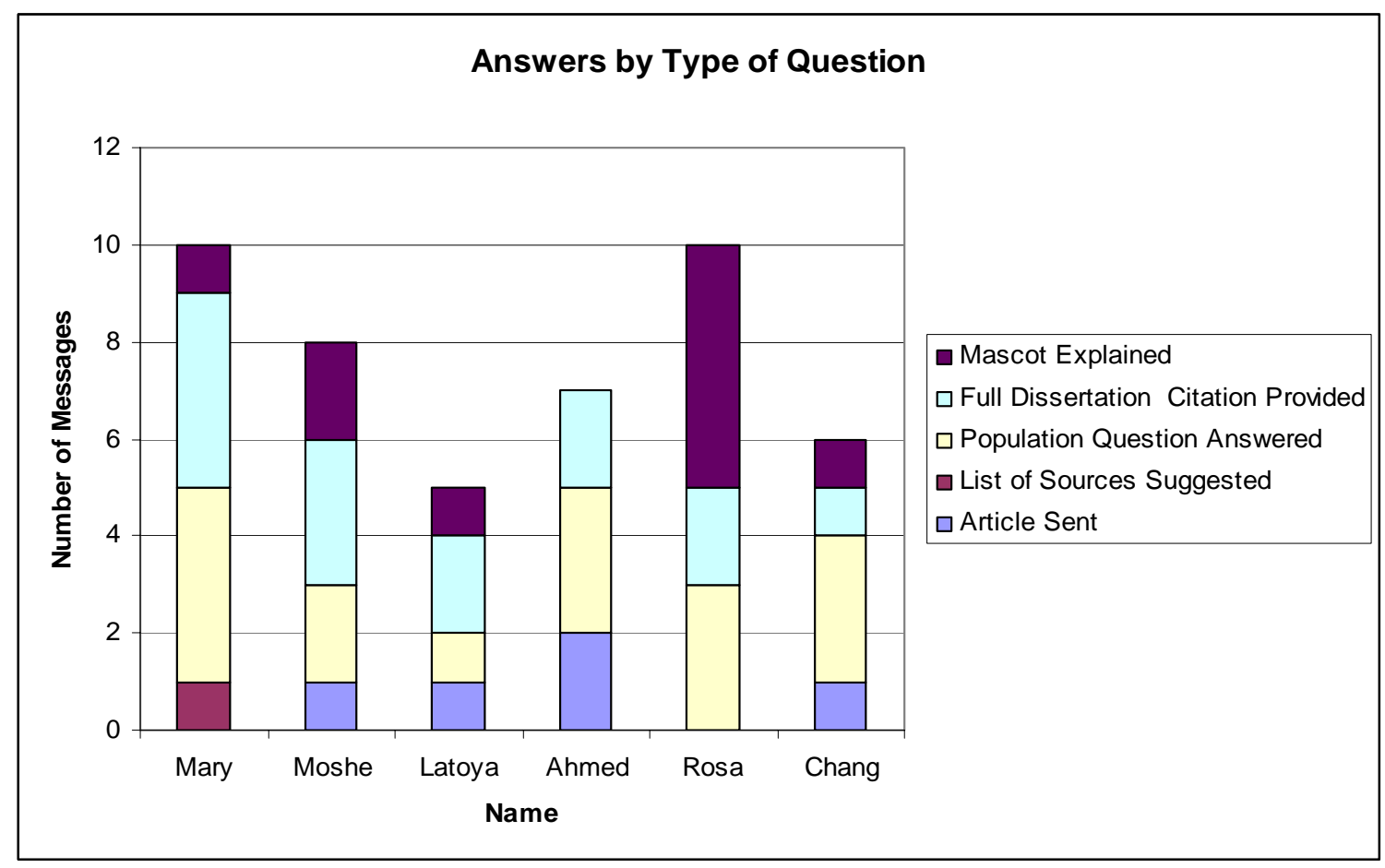

Fig. 5. Answers received by type of question per user.

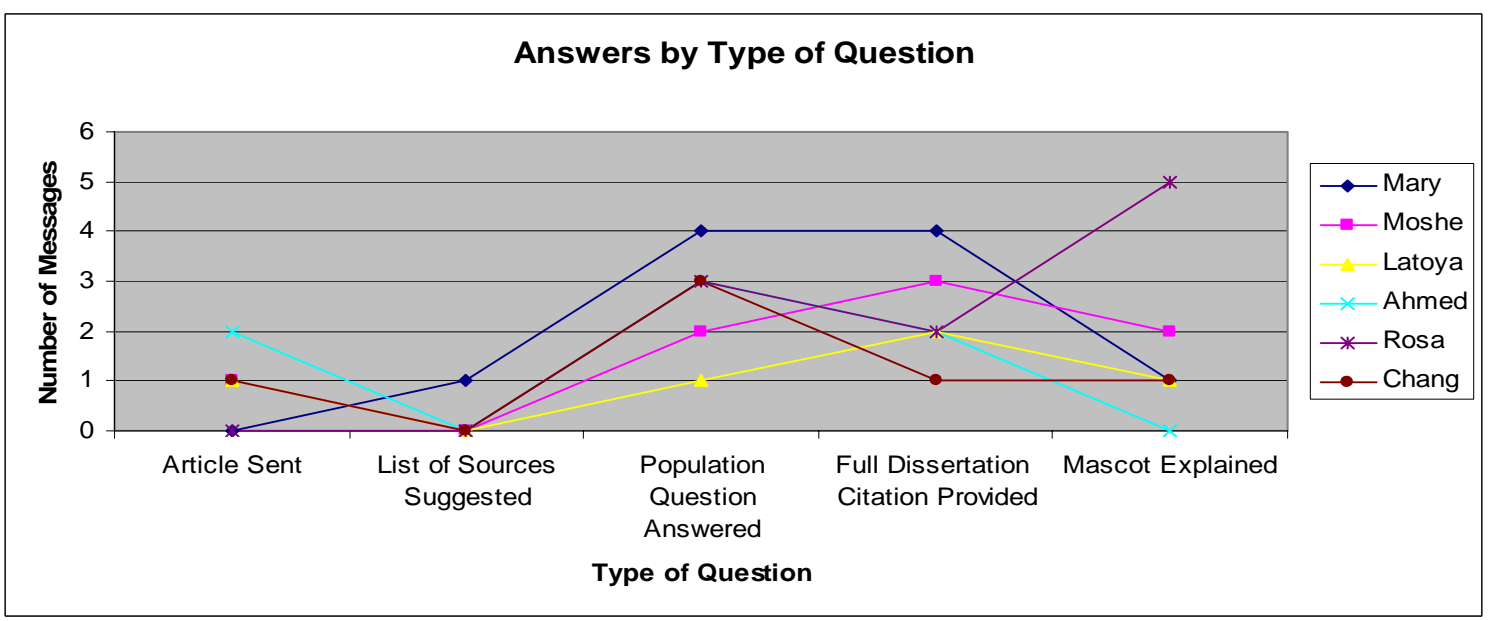

Fig. 6. Answers received by user per type of question.

Another indication of the quality of service is the way the librarian addresses the user. Fig. 8 illustrates the different frequencies of greetings, use of first and full name, and honorific use for each user. Yet again, Ahmed gets the lowest level of service, with no single case of honorific and a lower frequency of first name use. 


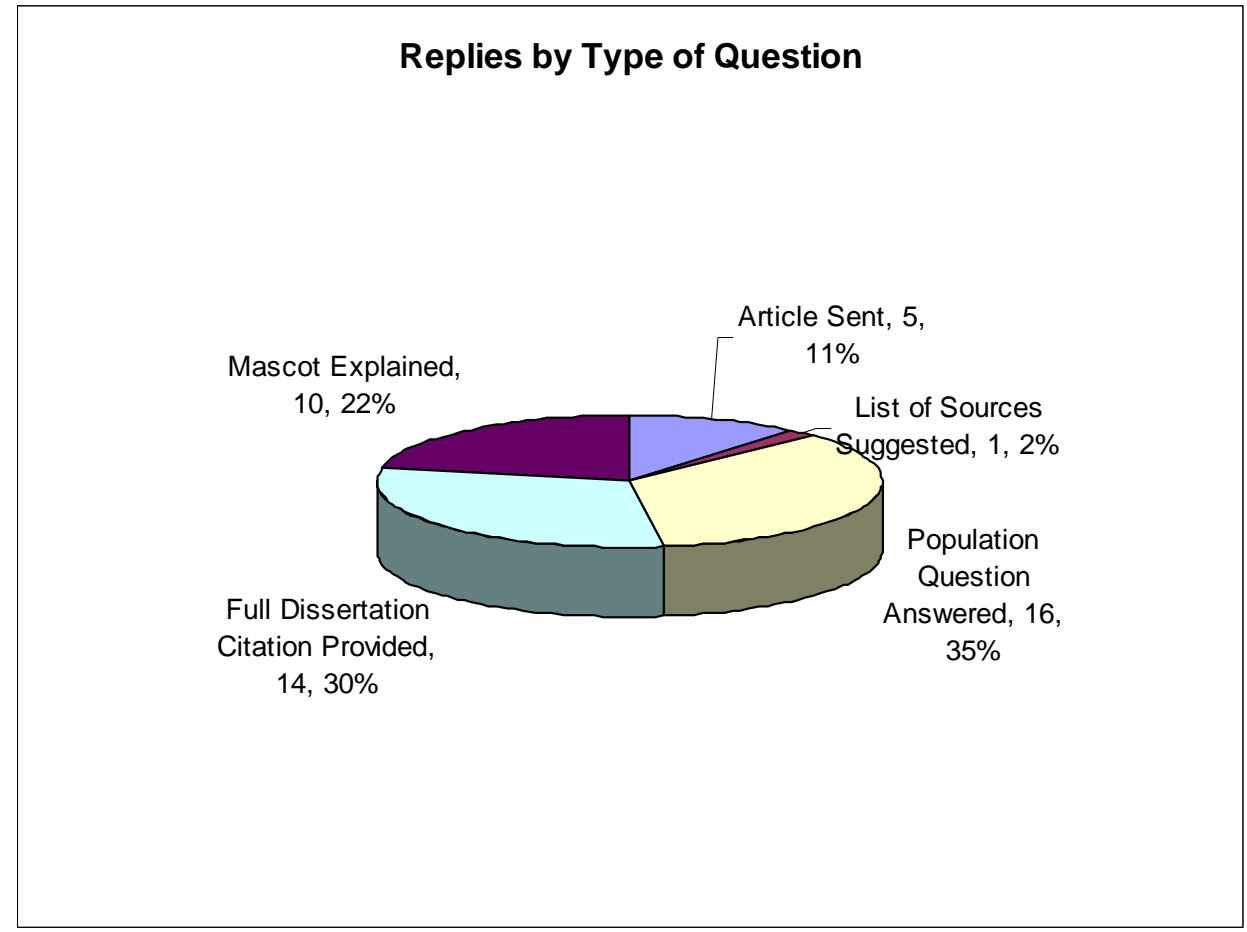

Fig. 7. Answers received by type of question.

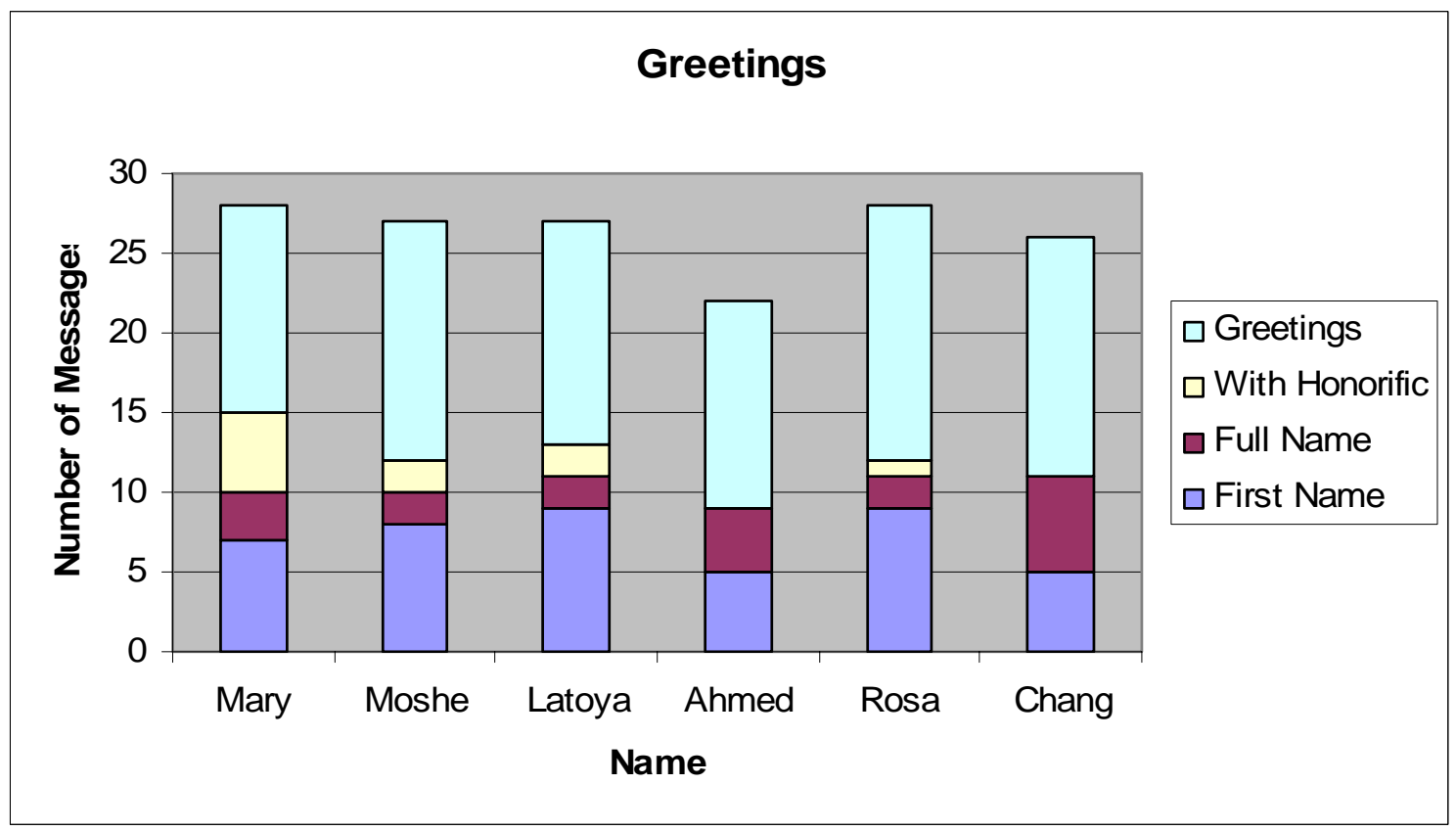

Fig. 8. Librarian greetings. 
Along these lines, Fig. 9 describes the frequencies of the professional endings that librarians included in their replies to each of the users. As the high bars indicate, Moshe is getting the best level of service. In addition, the ways librarians sign the replies vary across different users. Fig. 10 illustrates this with frequencies bars for each user on each category of signature that was included in messages. The two bars in the middle represents lower frequencies of contact information, names, and thank you notes for Ahmed and Latoya.

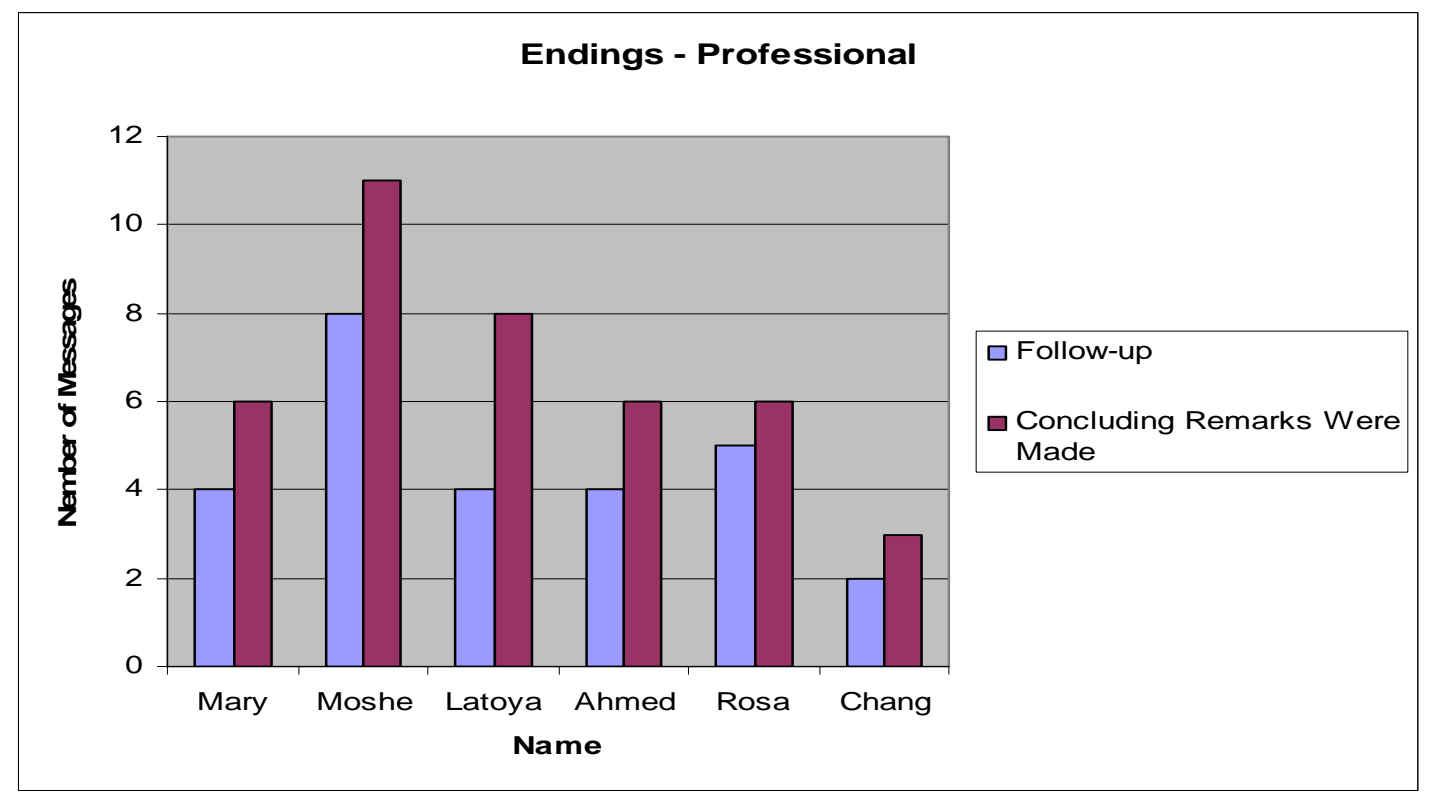

Fig. 9. Professional endings in librarians' messages.

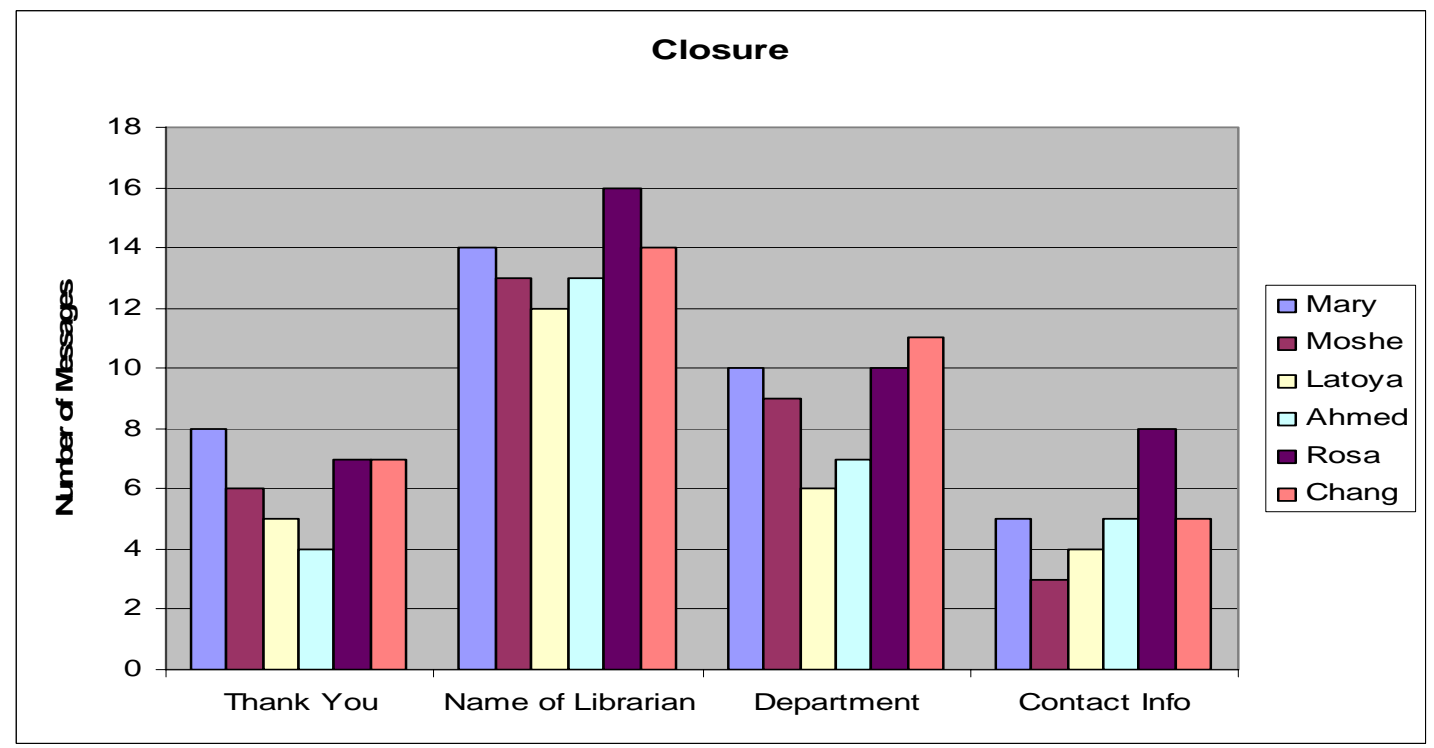

Fig. 10. Closure of librarians' messages. 


\section{Discussion}

As the findings show, on all codes and attributes that were examined in this study Latoya and Ahmed were discriminated against when compared with the level of service Moshe and Mary received. Poor service or avoidance of user information needs for long periods of time are discriminatory behaviors that were evident in the provision of online reference services to Arabs and African Americans when compared with White (Caucasian) Jewish or Christian users.

An examination of these findings in light of RUSA guidelines for behavioral performance of reference and information service providers (Reference and User Services Association, 2004a) and IFLA digital reference guidelines (International Federation of Library Associations, 2005) is the main focus of the discussion. Quotes from these guidelines illustrate the quality of virtual reference service that is expected from librarians as indicated by these professional associations. On the majority of these service quality aspects, the findings were in favor of Whites (Christian and Jewish users) over African American and Arabs; the quality of services to Asians and Hispanics were in between. For example, RUSA guidelines specify that:

Approachability behaviors, such as the initial verbal and non-verbal responses of the librarian, will set the tone for the entire communication process, and will influence the depth and level of interaction between the staff and the patrons. At this stage in the process, the behaviors exhibited by the staff member should serve to welcome the patrons and to place them at ease. The librarian's role in the communications process is to make the patrons feel comfortable in a situation that may be perceived as intimidating, risky, confusing, and overwhelming (Reference and User Services Association, 2004a, Item 1).

The different frequencies of greetings, use of first and full name, and honorific use for each user indicate an important aspect of reference service quality. Librarians' approachability, friendliness, and politeness were found by past researchers to affect user's satisfaction (Dewdney \& Ross, 1994 and Durrance, 1989). On this aspect of service Ahmed gets the lowest level of service, with no single case of honorific and lower frequency of first name. The lack of honorific could be interpreted as a lack of respect toward Ahmed. IFLA digital reference guidelines state that librarians should "Show professional courtesy and respect when answering questions" (International Federation of Library Associations, 2005). Findings indicate that librarians respected Moshe and Mary more than they respected Ahmed. At the same time using first name could indicate friendliness (or lack thereof). Ahmed and Chang were less frequently addressed by first name compared with the other users. It should be clarified, however, that both Chang $\mathrm{Su}$ and Ahmed Ibrahim are challenging names. Distinguishing between first name and last name in these two cases is not simple. Ahmed Ibrahim can as well be Ibrahim Ahmed, and Chang $\mathrm{Su}$ can be Su Chang. It is also possible that in the case of Chang $\mathrm{Su}$ a confusion about user gender resulted in librarians addressing the user by full name instead of first name and not using an honorific, which would have to be gender specific. Even more, Chinese often change the order of first and last name, which makes it 
difficult to decide on one of the two. For these reasons, it is possible that the lower amount of first name use is not entirely an indication of less friendly librarians.

In addition to greeting, IFLA guidelines specify that librarians should structure their responses to include a heading, body, and closure as stated in the following quote:

Heading: Greet patron, include a generic notice of thanks for using the service, refer directly to subject of patron's inquiry... Body: Cite sources fully, and in a consistent citation style... Signature: A signature should be a part of every closure. The librarian signature may contain librarian name or initials, title, institution and any contact information, as is prescribed by supervisor. Examples: "We hope the information we've provided will assist you with your research"; "I hope you find this information helpful"; "We hope this answers your question. If you have further questions, please contact us again and we will be glad to provide additional assistance...” (International Federation of Library Associations, 2005)

As these guidelines indicate, the ways in which librarians end their replies is an important aspect of quality service; yet, the endings and signature vary across the different user groups. In the messages to Moshe, librarians follow their professional guidelines for providing effective reference service and provide more concluding and follow-up remarks (compared with the other user groups). In addition, the ways in which librarians sign the replies vary across different users. It should be stressed that signatures and endings could well be a result of institutional or departmental policies and thus should be applied in a similar manner to all users. Nonetheless, lower frequencies of contact information, librarians' names, and thank you notes were found in the replies sent to Ahmed and Latoya compared with the other user groups. Thus, Ahmed and Latoya received poor service while Moshe received the highest level of service on these aspects.

RUSA guidelines specify that an important aspect of quality reference service is that the librarian shows interest in the user's request, even when it is not intellectually stimulating or challenging. The guidelines specify:

A successful librarian must demonstrate a high degree of interest in the reference transaction.... Librarians who demonstrate a high level of interest in the inquiries of their patrons will generate a higher level of satisfaction among users. To demonstrate interest, the librarian:... Acknowledges user email questions in a timely manner (Reference and User Services Association, 2004a, Item 2).

Librarians' interest in the users' request is reflected in the response time; it is an important indication of the quality of the reference service. IFLA guidelines concur and state that librarians should: "Acknowledge receipt of patron question. Provide patrons with responses as quickly as possible. Letters and other forms of communication should be answered promptly and courteously" (International Federation of Library Associations, 2005). If users receive a response to their queries quickly, they will be more satisfied with the service than if the librarian takes a long time to respond. Receiving a reply within the shortest period of time indicates a better level of service. IFLA guidelines 
continue and state that librarians should "...create and adhere to stated response turnaround policy" (International Federation of Library Associations, 2005). The expected response time was two business days, as stated in most of the studied libraries' response time polices. The findings indicate that the average response time to Moshe and Mary is shorter compared with Ahmed and Latoya. Similarly, the number of days it takes for each of the users to get a reply indicates a better level of service to Moshe and Mary and a much lower level of service to Ahmed and Latoya. It is most likely that a user who receives a reply a month after asking for information will not be satisfied with the service. The variations in response time again indicate discriminatory behaviors of avoidance or poor service. The most frequent type of discrimination in public accommodations that was reported by African Americans involves avoidance or poor service (Feagin, 1991).

Along these lines, it is assumed that if the librarian puts more time into responding to a user request and writes a longer message, a higher quality of response will result. The length of the reply (number of words) that Moshe receives is much higher than any other user; Mary does not get as good service as Moshe, but hers is still better than any of the other users. Moreover, when a user receives many messages but still does not receive a reply to the information need, the user will not be satisfied with the service. Again, Moshe and Mary are getting a higher level of service than the other user groups while the level of service for Ahmed and Latoya is the lowest in terms of length of reply and proportion of messages to answers.

Certain types of questions could potentially trigger different levels of service to various user groups while other types of questions will not. It is possible that a librarian will not only prefer to help certain user groups more than others but will also avoid declining a request from favorable user groups and at the same time will decline such services from unfavorable user groups. Bushman and Bonacci (2004), who examined discrimination against Arabs, report that certain individuals are more likely to discriminate against an Arab and to provide bad news rather than good news to an Arab. Along these lines, it is possible that a librarian will behave differently when either providing or refusing to provide a service. It is possible that refusing a user's request (e.g., as a response to the request for full-text article) will evoke different reactions than helping users. For that reason, this study had two groups of requests, the first three requests (dissertation, mascot, and population), which are expected to be answered by the librarian, and the next two (full-text article and topical), which are not. Due to institutional policies and licensing agreements, a librarian was expected to provide an answer to the first three questions but be disinclined to do so for the next two questions. The terms of use, in the agreements the library signed with the information owners, usually restrict access to affiliated (and walk in) users. IFLA guidelines further specify that librarians should "comply with contractual licensing agreements, for both electronic and print materials, as well as specific restrictions of use, and any copyright laws governing the materials in question" (International Federation of Library Associations, 2005). Overall, librarians comply with these guidelines towards all users. It is rare that the librarians provide the full text of an article to unaffiliated users. However, it should be anecdotally mentioned here that Ahmed received more full-text articles than any other user (a service that he, 
like the other users in our study, was not supposed to get as an unaffiliated user). But when he received the article in one case (out of two full-text articles that he received), he also received another message from the librarian apologizing for sending him the article that he was not supposed to get as an unaffiliated user. Despite his receipt of these articles, on almost any type of question Ahmed gets fewer answers than Mary does (and the same can be said of Latoya).

Service discrimination against Arabs and African American by reference librarians should not be the norm. While this study has not examined these behaviors at the level of an individual librarian, the users were discriminated against by individual librarians. Performance evaluation of reference librarians, like other service providers, should also look at how an individual librarian treats diversity and, more specifically, assess if a librarian provides unbiased service and does not discriminate against users based on race, gender, ethnicity, national origin, or religion. While this type of assessment in face-toface interactions might not be feasible, virtual reference services, which archive older transactions, enable such evaluation. In corporate America, such evaluations have been proposed; it was emphasized as a way to facilitate diversity management (Allen et al., 2004 and Swanson, 2002). "The managers' performance reviews should include how well they manage diversity. This task of reinforcement and maintenance ... falls upon the managers and the respective styles that they model for everyone else in the group" (Swanson, 2002, p. 259). They "should be willing to hold subordinates accountable for achieving these objectives ... [a] major issue of control is holding a subordinate accountable for violations of diversity policies" (Allen et al., 2004, p. 14). A library that would like to improve virtual reference services equality can hide user names from librarians and insert the names back (automatically) into the response that is sent to the user. This can be further facilitated by using a different field to insert first name and last name to avoid confusion when dealing with unfamiliar or other challenging names. A library that would like to improve equality of services can:

- Increase the awareness of librarians to their subjective bias through training. This can be done through routine diversity training sessions for virtual reference librarians and diversity training for librarians in general.

- Managers of reference librarians and researchers could include service equality in the evaluation of virtual reference services.

- Managers can include equality of services as part of a performance evaluation.

- LIS schools should emphasize the importance of providing equitable services to different user groups online and face-to-face.

- Libraries and LIS schools should make more efforts to recruit minorities to the library profession.

The discriminatory behavior of virtual reference services could be explained by the flaws of the virtual environment, where it is easier to behave in less socially accepted ways. It 
may as well be explained by other factors, such as the relative homogeneity of librarians. The library profession is overwhelmingly White, homogeneity that does not reflect the diverse composition of its users (Adkins \& Espinal, 2004). This composition does not provide many opportunities for direct contact with colleagues from different backgrounds and provides an ideal atmosphere for stereotypes, prejudices, and discrimination to flourish. One of the ways that the libraries can improve the level of service to diverse users groups is by increasing the efforts to recruit underrepresented groups in the library profession. However, this is not an easy task because "a significant portion of librarians consider libraries racist working environments" (Curry, 1994, p. 305).

Generalizations about these findings should be made with caution. Although the findings show that librarians provide different levels of service to different users on all the aspects that have been examined, the sample size is not large enough for generalization, and future studies should examine more transactions to determine if these differences are statistically significant. Future research should also focus on reference equality at the physical reference desk because it is possible that reference librarians provide unequal levels of service only online. Further, it is possible that other online services (in the for profit sectors) will exhibit similar tendencies but at the same time it is possible that they will exhibit more or less inequality in their service. Likewise, other library services should be examined to determine equality of services. For example, the level of service that librarians provide to affiliated users might be higher and potentially more equitable. It is also possible that real time services and collaborative virtual reference services will exhibit different levels of equality.

Other research directions that future studies could aim at would be: Are there any differences in the geographical location of libraries and equitability of their services? Would the same result be found in public libraries or other academic institutions (not ARL libraries)? Are different attitudes evident between public and private institutions of higher education? Do services in other countries follow the same equitable pattern (codes of ethics for librarians around the globe discuss equitable service, but practices may differ)? Can one expect requests from different nationalities to be answered with/without bias? Can one expect that the level of accuracy of responses will be affected by this bias as well? These are only some of the questions that this study raises for future research.

\section{Conclusion}

Virtual reference librarians discriminated against Arabs and African Americans and provided the best level of service to Caucasians (Christian and Jewish). This discriminatory pattern was evident on all the dimensions of service quality that were evaluated. Librarians ignored requests made by Arabs and African American users more than other users, responded more slowly to their requests, put less time and effort into the reply, and when replying to these users' requests did not adhere to professional guidelines as much as they did when replied to Caucasian users' requests.

Do librarians exemplify a new type of racism in their virtual reference services? Librarians may not be actively endorsing racist activities, but they are in control of a 
great deal of power through their ability to provide complex services and answer user requests over the Internet. Are librarians abusing their power by controlling and censoring access to information based on race, gender, religion, or national origin? The findings presented above suggest that they may, even if not intentionally.

\section{References}

Abels, E. G. (1996). The e-mail reference interview. Reference Quarterly, 35(3), 345-358.

Adkins, D., \& Espinal, I. (2004). The diversity mandate. Library Journal, 129(7), 52-54.

Allen, R., Dawson, G., Wheatley, K., \& White, C. S. (2004). Diversity practices: Learning responses for modern organizations. Development and Learning in Organizations, 18(6), 13-15.

American Library Association (1995). Code of ethics of the American Library Association. Retrieved February 20, 2005, from http://www.ala.org/ala/oif/statementspols/codeofethics/codeethics.htm

Bushallow-Wilbur, L., DeVinney, G., \& Whitcomb, F. (1996). Electronic mail reference service: A study. Reference Quarterly, 35(3), 359-371.

Bushman, B. J., \& Bonacci, A. M. (2004). You've got mail: Using e-mail to examine the effect of prejudiced attitudes on discrimination against Arabs. Journal of Experimental Social Psychology, 40(6), 753-759.

Carter, D. S., \& Janes, J. (2003). Unobtrusive data analysis of digital reference questions and service at the Internet Public Library: An exploratory study. Library Trends, 49(2), 251-265.

Civil Rights Act of $1964 \S 201,42$ USC, § 2000(a) (1964).

Coffman, S. (2003). Going live: Starting and running a virtual reference service. Chicago: American Library Association.

Coffman, S., \& Arret, L. (2004). To chat or not to chat: Taking yet another look at virtual reference. The Searcher, 12(8), 49-56.

Curry, D. A. (1994). Your worries ain't like mine: African American librarians and the pervasiveness of racism, prejudice and discrimination in academe. Reference Librarian, 45/46, 299-311.

Curry, A., \& Copeman, D. (2005). Reference service to international students: A field stimulation research study. Journal of Academic Librarianship, 31(5), 409-420.

Dewdney, P., \& Ross, C. S. (1994). Flying a light aircraft: Reference service evaluation from a user's viewpoint. Reference Quarterly, 34(2), 217-230.

Douglas, K. M., \& McGarty, C. (2001). Identifiability and self-presentation: Computermediated, communication and intergroup interaction. British Journal of Social Psychology, 40(3), 399-416.

Durrance, J. (1989). Reference success: Does the 55 percent rule tell the whole story? Library Journal, 114, 31-36.

Feagin, J. (1991). The continuing significance of race: Antiblack discrimination in public places. American Sociological Review, 56(1), 101-116. 
Glaser, J., \& Kahn, K. B. (2005). Prejudice and discrimination and the Internet. In Y. Amichai-Hamburger (Ed.), The social psychology of the Internet (pp. 247-274). Oxford: Oxford Univ. Press.

Gross, M., \& Saxton, M. L. (2002). Integrating the imposed query into the evaluation of reference service: A dichotomous analysis of user ratings. Library \& Information Science Research, 24, 251-263.

Hernon, P., \& Calvert, P. (2005). E-service quality in libraries: Exploring its features and dimensions. Library \& Information Science Research, 27, 377-404.

Hernon, P., \& McClure, C. R. (1986). Unobtrusive reference testing: The 55 percent rule. Library Journal, 111(7), 37-41.

International Federation of Library Associations (2005). IFLA digital reference guidelines. $\quad$ Retrieved January 5, 2006, from http://www.ifla.org/VII/s36/pubs/drg03.htm

Kaske, N., \& Arnold, J. (2002). An unobtrusive evaluation of online real time library reference services. Retrieved February 20, 2005, from http://www.lib.umd.edu/groups/digref/kaskearnoldunobtrusive.html

Liu, M., \& Redfern, B. (1997). Information seeking behavior of multicultural students: A case study at San Jose State University. College and Research Libraries, 58, 348-354.

McClure, C., Lankes, R. David, Gross, M., \& Choltco-Devlin, B. (2002). Statistics, measures and quality standards for assessing digital library services: Guidelines and procedures. ERIC Clearinghouse. Retrieved December 22, 2005, from http://quartz.syr.edu/rdlankes/tiki-download_file.php?fileId=7

Reference and User Services Association (2004a). Guidelines for behavioral performance of reference and information service providers. Retrieved January 5, 2006 , from http://www.ala.org/ala/rusa/rusaprotools/referenceguide/guidelinesbehavioral.htm

Reference and User Services Association (2004b). Guidelines for implementing and maintaining virtual reference services. Retrieved September 20, 2005, from http://www.ala.org/ala/rusa/rusaprotools/referenceguide/virtrefguidelines.htm

Shachaf, P. (2005). Bridging cultural diversity through email. Journal of Global Information Technology Management, 8(2), 46-60.

Shachaf, P., Hara, N., Meho, L., Kwon, N., Li, B., Sakai, Y., \& Lankes, D. (2005). Crosscultural analysis of virtual reference. [electronic version]. Proceedings of the 68th Annual Meeting of the Society for Information Science and Technology, vol. 42.

Sproull, L., \& Keisler, S. (1986). Reducing social context cues: Electronic mail in organizational communication. Management Science, 32, 1492-1513.

Stacy-Bates, K. (2003). E-mail reference responses from academic ARL libraries: An unobtrusive study. Reference and User Services Quarterly, 43(1), 59-70.

Swanson, D. R. (2002). Diversity programs: Attitude and realities in the contemporary corporate environment. Corporate Communications: An International Journal, 7(4), 257-268.

White, M. D. (2001). Digital reference services: Framework for analysis and evaluation. Library \& Information Science Research, 23, 211-231.

Whitlatch, J. B. (1989). Unobtrusive studies and the quality of academic reference services. College and Research Libraries, 50(2), 181-194. 
Whitlatch, J. B. (2001). Evaluating reference services in the electronic age. Library Trends, 50(2), 207-217.

Whitmire, E. (1999). Racial differences in the academic library experiences of undergraduates. Journal of Academic Librarianship, 25(1), 33-37.

Whitmire, E. (2003). Cultural diversity and undergraduates' academic library experiences. Journal of Academic Librarianship, 29(3), 148-161.

Zoe, L. R., \& DiMartino, D. (2000). Cultural diversity and end-user searching-An analysis by gender and language background. Research Strategies, 17(4), 291-305.

\section{Footnotes:}

${ }^{1}$ An example of the chronological order, user name, and type of questions a particular institution received as part of this study is given below. Week 1: Mary Anderson-Could you tell me the population of [city name] in 1963 and 1993? Week 2: Moshe CohenCould you help me find information about [special collection topic]? Can you send me copies of articles on this topic? Week 3: Ahmed Ibrahim - Can you send me by e-mail a copy of the article "Free Indirect Discourse and Narrative Authority in Emma" by D.P. Gunn? Week 4: Latoya Johnson-Can you tell me the title of [author]'s dissertation? He finished his degree at [institution name] in 1964. Do you have it in your library? How can I obtain a copy of this dissertation? Week 5: Rosa Manuz-How did [sports team name] become the name for [institution name]'s sports teams? Can you refer me to a book or article that discusses it? Week 6: Chang $\mathrm{Su}-$ Repeated question. 